\title{
The Eighteenth-Century Origins of Angina Pectoris: Predisposing Causes, Recognition and Aftermath
}

\author{
by Leon Michaels
}

In 1768. William Hebcrcen (1710-1801) made a presentation to the Royal College of Physicians of London describing angina pectoris in a manner readily recognizable to the twentieth-century physician. Previous accounts of symptoms such as those described by Heberden had been extremely few. The thesis of Leon Michaels' work is that. for all practical purposes. angina pectoris was a new. emerging condition that first appeared almost exclusively in England and as a result of the many changes in agriculture, eating habits and living patterns occurring during the eighteenth century. Michaels draws on the research of many disciplines including medical. agricultural and economic history, sociology, demography, and current food chemistry to produce a lucid and well-argued account of the rise of angina pectoris.

Leon Michaels. MD. PhD. I RCP was a clinical cardiologist and Associate Professor of Medicine at the University of Manitoba, Canada. He is currently President of the Manitoba History of Medicine Society.

Medical History, Supplement No. 21.231 pages, 11 illustrations, $€ 35$ or US\$55 (inclusive of p\&p) ISBN 0-85484-073-7

\section{New Publications Wellcome Witnesses}

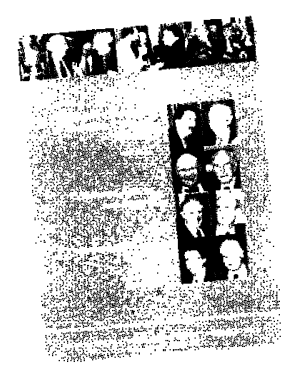

The Wellcome Irust Centre's History of Twentieth Century Medicine Group promotes

interaction between medical scientists. clinicians and historians of twentieth century medicine. A major component of the group's activity is to invite significant figures in twentieth-century medicine to participate in Witness Seminars, to discuss specific discoveries or events. debate their achievements and failures. and the consequences and impact of their work.

The resulting debates are published in the Wellcome Witnesses to Twentieth Century Mecicine series, two new volumes of which have just been published.

The first of these. volume 11, Childhood Asthma and Beyond, examines some of the major discoveries and developments in the management of childhood asthma over the past 30 years.

The second new addition to the series, volume 12. Maternal Cure, discusses a wide range of issues about the changing role of obstetricians, general practitioners, and the increasing status and responsibility of midwives.

Volumes cost $£ 5.00$ each and are available to order from the address below. Further information on the H.story of Twentieth Century Medicine Group and its work can be found on www.uci.ac.uk/histmed. A list of previously published volumes can also be found on the UCL. website address.

Please send orders to: Mrs Tracy Tillotson

Wellcome Library

183 Euston Road

London NW1 2BE, UK
Tel: $+44(0) 207611$ 8486; Fax: $+44(0) 2076118703$

E-mail: t.tillotson@wellcome.ac.uk

Payment in US\$ by credit card only. To pay in pounds sterling please send a cheque drawn from a UK bank account, or send credit card details.

THE WELLCOME TRUST CENTRE FOR THE HISTORY OF MEDICINE AT UCL 


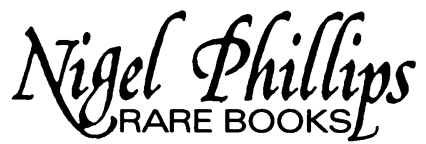

Antiquarian books in the history of medicine and the health sciences.

Please send for my catalogue, or telephone for an appointment when in London.

\section{BURLEIGH PLACE} PUTNEY

LONDON SW15 6ES

Tel: 02087882664

Fax: 02087801989

e-mail: nigel@nigelphillips.com

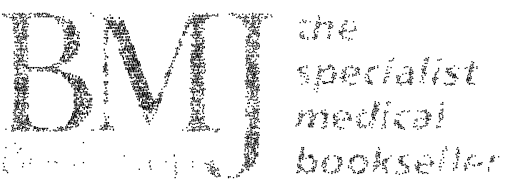

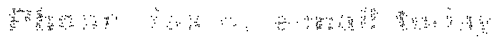

\section{Antiquarian Books concerning \\ Medicine, the Sciences \& Natural History}

Catalogues issued - Commissions \& Valuations undertaken Visitors welcome by Appointment

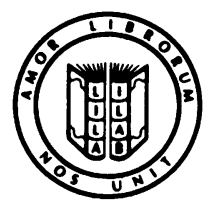

\section{MICHAEL PHELPS}

Allfreys House - Bolney Road

Cowfold · West Sussex RH13 8AZ

Telephone: +44 (0) 1403864049

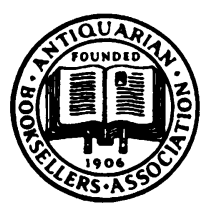

Fax: +44 (0) 1403864730 